\title{
Modelos de regressão com platô na estimativa do tamanho de parcelas em experimento de conservação in vitro de maracujazeiro
}

\author{
Using of regression plateau models in estimation of plot sizes for experiments with passion fruit
}

\author{
Ana Patricia Bastos PeixotoI Gláucia Amorim Faria' ${ }^{\mathrm{II}}$ Augusto Ramalho de Morais ${ }^{\mathrm{II}}$
}

\section{RESUMO}

\begin{abstract}
A determinação do tamanho de parcela é uma prática pertinente ao planejamento experimental e sua caracterização otimizada, em conjunto com o controle do material experimental, permite a obtenção de resultados com maior precisão e qualidade. Neste trabalho, determinou-se o tamanho de parcelas para experimentos de conservação in vitro de maracujazeiro, em dez ensaios de uniformidade com a espécie Passiflora Giberti N. E. Brown, utilizando-se o modelo de regressão linear segmentado com platô e o modelo de regressão quadrática segmentado com platô, que utilizam a técnica de resposta com platô a modelos que possuam mínimo. Os ensaios de uniformidade foram oriundos de experimento conduzido no delineamento inteiramente casualizado, com 20 unidades básicas (ub), e os tratamentos dispostos em esquema fatorial com três concentrações de sacarose, três concentrações de sorbitol e uma testemunha. A coleta dos dados foi realizada aos 60 dias após a incubação, medindo-se o comprimento das brotações. Os tamanhos de parcelas variaram com o método utilizado, encontrando-se parcelas formadas por seis explantes pelo modelo da regressão linear segmentado com platô e de dez explantes pelo modelo de regressão quadrática segmentado com platô.
\end{abstract}

Palavras-chave: Passiflora Giberti N. E. Brown, precisão experimental, coeficiente de variação, ensaio de uniformidade, regressão segmentada.

\section{ABSTRACT}

The determination of the plot size is a practical question to the experimental design, and its characterization in an optimized way allows obtaining larger precision and quality results. This research aimed to determine the plot size in experiments in vitro that seek the passion fruit plant conservation in ten uniformity assays with the species Passiflora Giberti N. E. Brown. The tests of uniformity came from an experiment conducted in a completely randomized design with treatments in a factorial design with three concentrations of sucrose, three concentrations of sorbitol and a control. Each treatment was considered as a uniformity assay, with 20 basic units. The evaluations of the experiments were done in the 60 days of incubation, being measured the shoots' length. For the estimate of the optimal plot size it was used the models segmented with linear-plateau, and the quadratic-plateau. The plot size varied with the method used, with values from 6 basic units for the linear-plateau model segmented, and from 10 basic units, for quadratic-plateau model.

Key words: Passiflora Giberti N. E. Brown, experimental precision, variation coefficient, uniformity assay, segmented regression.

\section{INTRODUÇÃO}

A conservação in vitro por cultura de tecidos é uma técnica que vem sendo utilizada e aperfeiçoada na manutenção dos bancos ativos de germoplasma. Em trabalhos de conservação, geralmente se utiliza o maior número de repetições possível por tratamento, em razão da grande variabilidade do material biológico a ser testado e do tempo que esse material será testado sem subcultivo. Isso acarreta maior custo

'Departamento de Estatística, Universidade Estadual da Paraíba (UEPB), 58429-500, Campina Grande, PB, Brasil. E-mail: anapatricia@cct.uepb.edu.br. Autor para correspondência.

"Programa de Pós-graduação em Estatística e Experimentação Agropecuária, Universidade Federal de Lavras (UFLA), Lavras, MG, Brasil.

IIIDepartamento de Ciências Exatas, UFLA, Lavras, MG, Brasil. 
do experimento, maior tempo para avaliação e gasto de material de consumo, podendo até limitar a execução de projetos pelo aumento de seu custo de financiamento pelas agências de fomento.

Assim, o planejamento experimental adequado quanto ao tamanho de parcela e do número de repetições pode propiciar sucesso na conservação de materiais genéticos (STORCK et al., 2005). O tamanho ótimo de parcela é uma das maneiras fundamentais de se promover o aumento da precisão experimental e, consequentemente, gerar a maximização das informações coletadas no experimento. $\mathrm{O}$ método proposto por SMITH (1938) é o precursor de vários outros métodos para determinar o tamanho de parcelas, o qual é baseado na relação entre variância dos totais de parcelas de diferentes tamanhos e o tamanho de parcela. O método da máxima curvatura (LE CLERG, 1967), método da curvatura máxima (LESSMAN \& ATKINS, 1963) e o método da máxima curvatura modificado (MEIER \& LESSMAN, 1971) são os mais utilizados na determinação do tamanho das parcelas, utilizando para isso a relação entre o coeficiente de variação e o tamanho da parcela. PARANAÍBA et al. (2009a, 2009b) propuseram a utilização de método baseado no modelo linear de resposta com platô para estimar o tamanho de parcela.

A definição do número de explantes por parcela, em experimentos de micropropagação, tem sido feito de modo empírico, com base na experiência do pesquisador. Por exemplo, PASSOS et al. (2004) utilizaram parcela constituída por um frasco com cinco sementes e dez repetições, para verificarem o efeito de doses de ácido giberélico, associado com presença e ausência de luz na germinação de sementes de Passiflora nítida. Avaliando transformações genéticas no maracujazeiro para resistência ao vírus do endurecimento dos frutos, TREVISAN \& MENDES (2005) utilizaram o delineamento inteiramente casualizado, com cinco repetições, cada repetição constituída de uma magenta com cinco explantes. Já, em experimento de estabelecimento in vitro de maracujazeiro, FARIA et al. (2007) usaram parcelas formadas por uma magenta contendo um explante, e LIMA et al. (2008) usaram o delineamento inteiramente casualizado, sendo cada tratamento repetido 20 vezes e cada parcela formada por um tubo, cada tubo contendo um explante. VILLA et al. (2008) utilizaram parcela constituída por três tubos, contendo um explante em cada.

Dessa forma, o objetivo deste trabalho foi de estimar o tamanho ótimo de parcelas para experimentos de conservação in vitro de maracujá Passiflora giberti N. E. Brown, utilizando-se o modelo de regressão linear segmentado com platô e o modelo de regressão quadrático segmentado com platô.

\section{MATERIAL E MÉTODOS}

Os dados utilizados foram provenientes de experimento conduzido no Laboratório de Biotecnologia Vegetal da Embrapa Mandioca e Fruticultura, em Cruz das Almas, Bahia, utilizando-se, como material vegetal, segmentos nodais com aproximadamente 1 (um) $\mathrm{cm}$ de comprimento, de plantas de maracujazeiro Passiflora giberti N. E. Brown, oriundos do Banco Ativo de Germoplasma da Embrapa Mandioca e Fruticultura.

Os segmentos (explantes) de plântulas cultivados in vitro foram dispostos em magentas ${ }^{\circledR}$ contendo $20 \mathrm{~mL}$ do meio de cultura MS, suplementado com $10,20 \mathrm{e} 40 \mathrm{~g} \mathrm{~L}^{-1}$ de sorbitol combinados com $0,15 \mathrm{e}$ $30 \mathrm{~g} \mathrm{~L}^{-1}$ de sacarose, mais uma testemunha com meio MS padrão, contendo $30 \mathrm{~g} \mathrm{~L}^{-1}$ de sacarose. Todos os tratamentos foram gelificados com $2 \mathrm{~g} \mathrm{~L}^{-1}$ de phytage $^{\circledR}$, ajustados a um pH de 5,8 e sem adição de fitoreguladores. $\mathrm{O}$ cultivo foi realizado sob condições de fotoperíodo de 16 horas, temperatura de $27 \pm 1^{\circ} \mathrm{C}$ e densidade de fluxo de fótons $22 \mu \mathrm{E} \mathrm{m}^{-2} \mathrm{~s}^{-1}$, permanecendo nessas condições por 60 dias.

Utilizou-se o delineamento inteiramente casualizado com os tratamentos dispostos em esquema fatorial $3 \times 3+1$, com 10,20 e $40 \mathrm{~g} \mathrm{~L}^{-1}$ de sorbitol combinados com 0,15 e $30 \mathrm{~g} \mathrm{~L}^{-1}$ de sacarose, mais uma testemunha com meio MS padrão, contendo $30 \mathrm{~g} \mathrm{~L}^{-1}$ de sacarose. Cada um dos 10 tratamentos foi considerado como um ensaio de uniformidade, sendo cada ensaio constituído por 20 unidades básicas (ub). Cada unidade básica foi constituída de um explante por magenta ${ }^{\circledR}$. A avaliação dos ensaios foi realizada aos 60 dias após incubação, observando-se o comprimento das brotações $(\mathrm{cm})$.

As unidades básicas em cada ensaio foram dispostas aleatoriamente e convenientemente com número diferentes de linhas e colunas. Após essa disposição, construíram-se 15 diferentes tamanhos de parcela, formados por $X_{1}$ unidades básicas na linha e $X_{2}$ unidades básicas na coluna. Os tamanhos de parcela foram simulados pelo agrupamento de unidades básicas adjacentes, de modo que $X_{1} X_{2}$ correspondesse a $X$ (tamanho da parcela em número de unidades básicas).

Para cada simulação, foram estimados os parâmetros: número de parcelas $(N)$, totais e médias das parcelas com $\mathrm{X}$ unidades básicas, variância por unidade básica e o coeficiente de variação $(C V)$, o qual foi usado como medida de variabilidade. Nas parcelas simuladas com diferentes formas, mas com o mesmo 
tamanho, foi considerada a média aritmética dos coeficientes de variação. Os métodos de estimação utilizados para determinar o tamanho ótimo de parcelas foram baseados no modelo de regressão linear segmentado com platô (LRP) e no modelo de regressão quadrático segmentado com platô (LRQ), conforme denominados de modelos lineares de resposta com platô por ANDERSON \& NELSON (1975).

O modelo de regressão linear segmentado com platô possui dois segmentos (SCHABENBERGER $\&$ PIERCE, 2002), o primeiro descreve uma reta crescente ou decrescente até um determinado valor $P$ da curva, que é o platô de resposta, e a partir desse o valor assume uma constante. Esse modelo pode ser representado por:

$C V_{i}=\left\{\begin{array}{lll}\beta_{0}+\beta_{1} X_{i}+\varepsilon_{i} & \text { se, } & X_{i} \leq X_{c} \\ P+\varepsilon_{i} & \text { se, } & X_{i}>X_{c}\end{array}, \quad\right.$ i $=1, \ldots, 10$

em que $C V$ é o coeficiente de variação entre totais de parcelas de tamanho $X_{\mathrm{i}}$, no i_ésimo ensaio de uniformidade; $X_{\mathrm{i}}$ é o número de unidades básicas agrupadas; $X_{\mathrm{c}}$ é o parâmetro relativo ao tamanho ótimo de parcelas para o qual o modelo linear se transforma em um platô, em relação à abscissa; $P$ é o coeficiente de variação no ponto correspondente ao platô; $\beta_{0}$ é o intercepto e $\beta_{1}$ o coeficiente angular do segmento linear e $\varepsilon_{\mathrm{i}}$ é o erro aleatório associado ao $C V_{\mathrm{i}}$, considerados independentes e normalmente distribuídos com média 0 e variância constante. $\mathrm{O}$ valor estimado de $\mathrm{X}_{\mathrm{c}}$ é o tamanho ótimo de parcelas (em unidades básicas) que será recomendado para esse tipo de experimento. Assim, o tamanho ótimo da parcela foi estimado pela expressão $X_{c}=\left(\hat{P}-\hat{\beta}_{0}\right) / \hat{\beta}_{1}$, em que $\hat{\beta}_{0}, \hat{\beta}_{1}$ e $\hat{\mathrm{P}}$ representam os valores das estimativas dos parâmetros do modelo (1).

O tamanho ótimo de parcela também foi estimado utilizando-se o modelo de regressão quadrática segmentado com platô, o qual é representado por uma fase decrescente ou crescente, descrita por uma equação do segundo grau e, após a estabilização, por um platô. O tamanho ótimo de parcelas é definido pelo ponto de encontro da função quadrática e o platô. Pensou-se na utilização desse modelo pelo fato de que, em geral, ocorre redução no coeficiente de variação, à medida que se aumenta o número de unidades básicas agrupadas por parcela, e essa redução pode apresentar um comportamento quadrático.

O modelo de regressão quadrático segmentado com platô é representado por:

$C V_{i}=\left\{\begin{array}{ll}\beta_{i}+\beta X_{i}+\beta_{2} X_{i}^{2}+\varepsilon_{i} & \text { se } X_{i} \leq X_{c} \\ P+\varepsilon_{i} & \text { se } X_{i}>X_{c}\end{array}\right.$, i=1,...,10(2) em que $\beta_{0}, \beta_{1,} \beta_{2}$ são parâmetros a serem estimados do primeiro segmento (quadrático) e os demais componentes do modelo têm definição idênticas aos do modelo (1).

Para valores de $\mathrm{X}_{\mathrm{i}}\left(\mathrm{X}_{\mathrm{c}}\right.$, os valores de $C V_{\mathrm{i}}$ são explicados por um modelo quadrático e, para valores de $X_{i}>X_{c}$, a equação explicativa é uma constante e paralela à abscissa. Esse ponto representa a junção do segmento quadrático com o segmento de platô. O ponto de junção entre o modelo quadrático e o platô define o tamanho ótimo de parcela, o qual é estimado por: $X_{c}=-\frac{\beta_{1}}{2 \beta_{2}}$. Substituindo $X_{\mathrm{c}}$ na expressão (2), obtém-se o valor correspondente ao platô, dado por $P=\beta_{0}-\frac{\beta_{1}^{2}}{4 \beta_{2}}$. Nesse caso, têm-se três parâmetros efetivos, pois tanto $X_{\mathrm{c}}$ quanto $P$ são determinados a partir de $\beta_{0}, \beta_{1} \mathrm{e} \beta_{2}$.

Todas as análises estatísticas foram realizadas utilizando-se de rotinas específicas do programa computacional livre $\mathrm{R}$ (R DEVELOPMENT CORE TEAM, 2010).

\section{RESULTADOS E DISCUSSÃO}

Por meio do ajuste do modelo linear segmentado com platô, observou-se uma grande variabilidade no coeficiente de variação, com valores variando de $2 \%$ (no T4 - $0 \mathrm{~g} \mathrm{~L}^{-1}$ de sacarose e $40 \mathrm{~g} \mathrm{~L}^{-1}$ de sorbitol) até próximos de $98 \%$ (no $\mathrm{T} 8-30 \mathrm{~g} \mathrm{~L}^{-1}$ de sacarose $10 \mathrm{~g} \mathrm{~L}^{-1}$ de sorbitol), como mostrado na figura 1 , sugerindo que a medida de variabilidade $(C V)$ difere bastante entre os tratamentos.

A aplicação do modelo de regressão linear segmentada com platô (LRP) permitiu descrever o comportamento da variabilidade medida pelo $C V$, ao longo dos tamanhos de parcelas simulados. Pode-se destacar que o ajuste do modelo de regressão com platô em todos os tratamentos pode ser considerado bom, com valores do coeficiente de determinação variando de $56,84 \%$ a $94,94 \%$ (Tabela 1). As estimativas do tamanho ótimo de parcela $\left(X_{\mathrm{c}}\right)$ variaram de 3 (ub) (T5 $15 \mathrm{~g} \mathrm{~L}^{-1}$ de sacarose e $10 \mathrm{~g} \mathrm{~L}^{-1}$ de sorbitol), correspondente a um coeficiente de variação de $12,75 \%$ no platô, a 8 (ub) (T2 - $0 \mathrm{~g} \mathrm{~L}^{-1}$ de sacarose e $10 \mathrm{~g} \mathrm{~L}^{-1}$ de sorbitol), representando um platô no coeficiente de variação de $7,92 \%$ (Tabela 1). Estes valores se encontram próximos aos utilizados por RIBAS et al. (2002) e MARTINEZ et al. (2005), que usaram parcelas formadas por seis explantes e bem diferentes aos usados por FARIA et al. (2007), que utilizaram parcelas com um explante. 


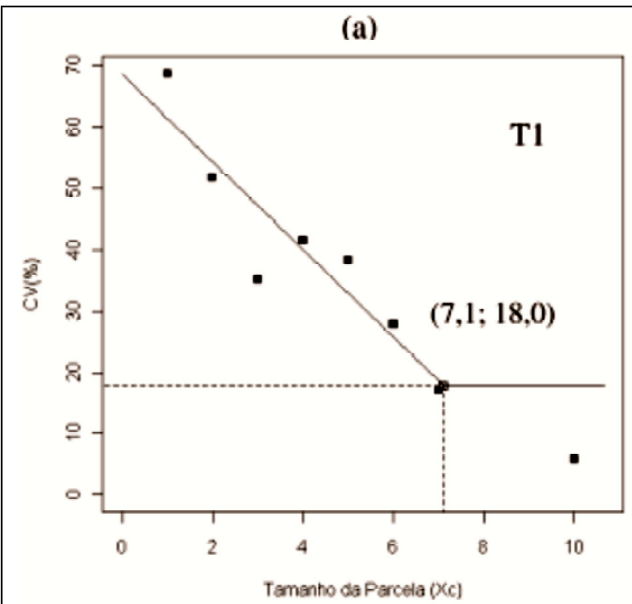

(c)

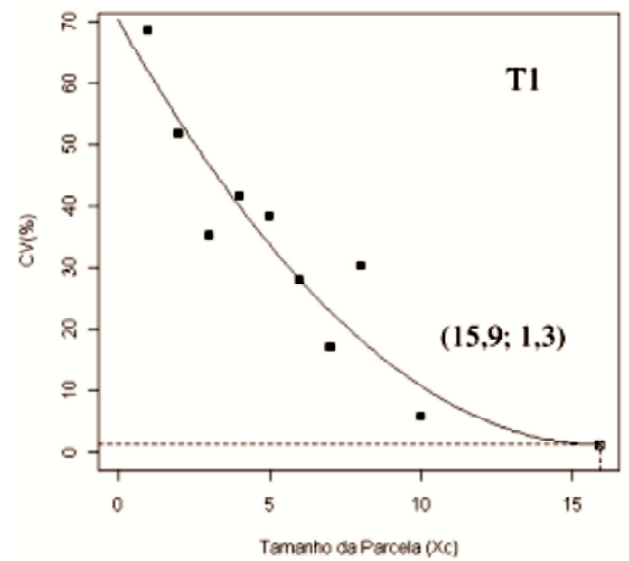

(b)

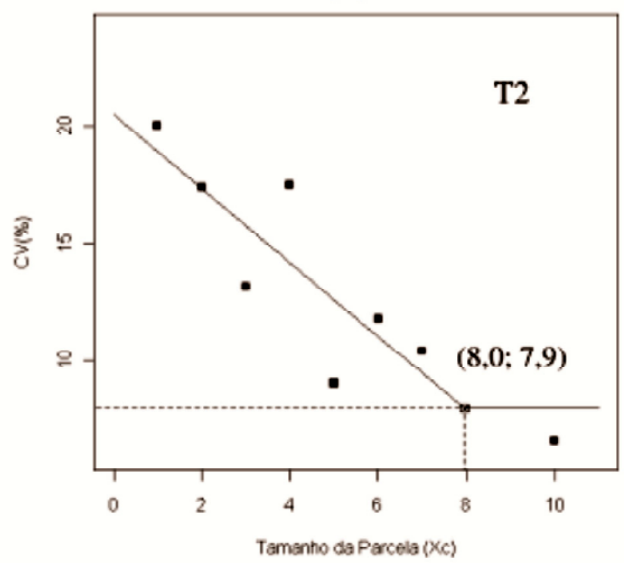

(d)

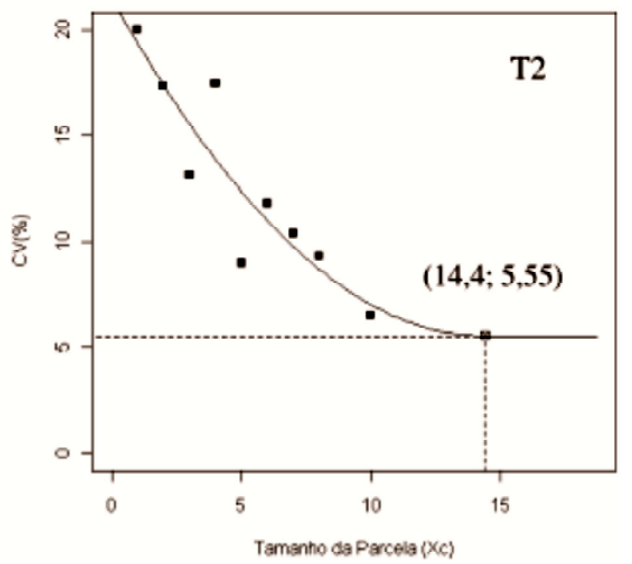

Figura 1 - Representação gráfica da relação entre o coeficiente de variação $(\mathrm{CV})$ do comprimento de brotação e tamanho ótimo da parcela $\left(\mathrm{X}_{\mathrm{c}}\right)$ em unidades básicas nos tratamentos (T1 a T2) para o método de regressão segmentada com platô linear (a e b), respectivamente, e (T1 a T2) para o método de regressão segmentada com platô quadrático (c e d), respectivamente, nos experimentos de conservação in vitro de maracujá.

De acordo com o modelo de regressão linear segmentado com platô, a partir do ponto $\left(X_{\mathrm{c}}\right)$, o tamanho de parcela se faz suficiente, não havendo mais necessidade de aumentá-lo, pois não se tem ganho substancial em aumento de precisão experimental. Esse fato sugere que o tamanho de parcela estimado por este método seja adequado, o que está de acordo com o trabalho de PARANAÍBA et al. (2009a), que verificaram ser o método LRP tão bom ou até melhor que o método da curvatura máxima.

Como o interesse maior éna avaliação global de todos os tratamentos, uma alternativa seria utilizar o maior tamanho de parcela; nesse caso, oito unidades básicas para constituir o tamanho ótimo de parcela. No entanto, uma sugestão mais cautelosa seria utilizar a média dos tamanhos de parcela dos diferentes tratamentos, aqui com 5,3 unidades básicas ou aproximadamente seis explantes, sendo economicamente mais viável.

As estimativas do tamanho de parcela obtidas pelo modelo de regressão quadrático segmentado com platô foram maiores do que aquelas calculadas pelo modelo de regressão linear segmentado (Tabela 2), provavelmente devido à curvatura do modelo no seu primeiro segmento. Os tamanhos de parcelas variaram de 5 a 16 unidades básicas, de acordo com o tratamento. Esses resultados estão próximos aos valores encontrados na literatura: como RIBAS et al. (2002) utilizaram para cada tratamento dez placas com seis explantes por parcela; COSTA \& AYUB (2002) utilizaram o delineamento em blocos aleatorizados, constituído de seis tratamentos com cinco repetições 
Tabela 1 - Estimativas dos parâmetros do modelo de regressão linear segmentado com platô, do coeficiente de variação no platô de resposta $(\mathrm{P})$, do tamanho ótimo de parcela $\left(\mathrm{X}_{\mathrm{c}}\right)$ no ponto de platô e do coeficiente de determinação $\left(R^{2}\right)$ para os diferentes tratamentos de conservação in vitro de maracujá.

\begin{tabular}{|c|c|c|c|c|c|}
\hline \multirow{2}{*}{ Tratamentos } & \multicolumn{2}{|c|}{ 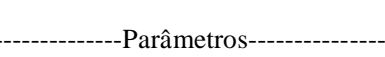 } & \multirow{2}{*}{$\begin{array}{c}\text { Coeficiente de } \\
\text { variação } \\
\text { P }\end{array}$} & \multirow{2}{*}{$\begin{array}{c}\text { Tamanho de parcela } \\
X_{\mathrm{c}}\end{array}$} & \multirow{2}{*}{$\begin{array}{c}\text { Coeficiente de } \\
\text { determinação } \\
\text { r2 }\end{array}$} \\
\hline & $\beta_{0}$ & $\beta_{1}$ & & & \\
\hline $\mathrm{T} 1$ & 68,562 & $-7,117$ & 18,03 & 7,1 & 0,8004 \\
\hline $\mathrm{T} 2$ & 20,511 & $-1,583$ & 7,92 & 8,0 & 0,7773 \\
\hline $\mathrm{T} 3$ & 57,320 & $-6,362$ & 11,70 & 7,2 & 0,9494 \\
\hline $\mathrm{T} 4$ & 13,140 & $-1,746$ & 2,90 & 5,6 & 0,8212 \\
\hline T5 & 104,217 & $-27,570$ & 12,75 & 3,3 & 0,9346 \\
\hline T6 & 51,224 & $-3,526$ & 31,73 & 5,5 & 0,5950 \\
\hline $\mathrm{T} 7$ & 36,140 & $-7,845$ & 8,57 & 3,5 & 0,7536 \\
\hline $\mathrm{T} 8$ & 116,053 & $-22,295$ & 36,68 & 3,6 & 0,8113 \\
\hline T9 & 49,334 & $-5,449$ & 12,18 & 6,2 & 0,5684 \\
\hline $\mathrm{T} 10$ & 20,894 & $-3,026$ & 4,03 & 5,6 & 0,8742 \\
\hline
\end{tabular}

* Média de 5,3 explantes no tamanho da parcela (platô linear).

contendo 10 explantes por placa; um pouco maiores que os três explantes por parcela usados por AIRES et al. (2007) e; os quatro usados por RIBEIRO et al. (2006).

Ao comparar os dois modelos com base nos valores dos coeficientes de determinação, o método de regressão quadrático proporciona melhores ajustes, o que era esperado, devido ao maior número de parâmetros. No entanto, um possível "falso" platô pode ser obtido ao se utilizar de modelos segmentados, pois nem sempre existe amplitude suficiente nos tamanhos e parcelas simulados para se alcançar uma resposta com platô, como é mais comum ocorrer com o modelo quadrático.

Os tamanhos de parcelas estimados não devem ser vistos como tamanho ótimo de parcela, mas como mínimos, pois suas estimativas variam em relação aos diferentes tratamentos, logo, também irão apresentar variações entre experimentos. Os valores dos tamanhos de parcelas estimados por meio dos modelos propostos encontram-se próximos aos usados em várias pesquisas, podendo ser utilizados como referência em experimentos de conservação in vitro de maracujazeiro. A caracterização de forma adequada da parcela confere maior precisão, endossa a inferência dos resultados, pois, segundo DONATO et al. (2008), independentemente dos objetivos dos experimentos, o que se procura detectar é a existência de diferenças significativas entre tratamentos testados.

Desse modo, sugere-se utilizar parcelas formadas por, no mínimo, 5,3 unidades básicas ou,

Tabela 2 - Estimativas dos parâmetros do modelo de regressão quadrático segmentado de com platô, do coeficiente de variação no platô de resposta $(P)$, do tamanho ótimo da parcela $\left(X_{c}\right)$ no ponto de platô e do coeficiente de determinação $\left(R^{2}\right)$ para os diferentes tratamentos de conservação in vitro de maracujá.

\begin{tabular}{llccccc}
\hline Tratamentos & -1 & & Coeficiente de \\
variação & $\begin{array}{c}\text { Tamanho de } \\
\text { parcela* }\end{array}$ & $\begin{array}{c}\text { Coeficiente de } \\
\text { determinação }\end{array}$ \\
& \multicolumn{1}{c}{$\beta_{0}$} & $\beta_{1}$ & $\beta_{2}$ & $\mathrm{P}$ & $X_{\mathrm{c}}$ & $\mathrm{r}$ \\
\hline T1 & 70,344 & $-8,683$ & 0,273 & 1,32 & 15,9 & 0,848 \\
T2 & 21,545 & $-2,225$ & 0,077 & 5,55 & 14,4 & 0,808 \\
T3 & 59,839 & $-8,498$ & 0,325 & 4,32 & 13,1 & 0,952 \\
T4 & 14,804 & $-2,955$ & 0,178 & 2,46 & 8,3 & 0,877 \\
T5 & 113,988 & $-41,425$ & 4,179 & 11,33 & 5,0 & 0,951 \\
T6 & 53,246 & $-5,129$ & 0,286 & 30,32 & 8,9 & 0,656 \\
T7 & 37,105 & $-9,941$ & 0,837 & 7,59 & 5,9 & 0,795 \\
T8 & 129,821 & $-38,476$ & 3,955 & 36,25 & 4,9 & 0,890 \\
T9 & 51,628 & $-6,571$ & 0,256 & 9,51 & 12,8 & 0,644 \\
T10 & 24,815 & $-5,992$ & 0,435 & 4,19 & 6,9 & 0,916 \\
\hline
\end{tabular}

* Média de 9,6 explantes no tamanho da parcela (platô quadrático). 
aproximadamente, seis explantes, para constituir a parcela experimental, correspondente à média dos tamanhos de parcelas entre os tratamentos, quando se utilizou o modelo de regressão linear segmentado. Caso haja disponibilidade de material, esse valor pode ser visto como um tamanho de parcela mínimo, podendo o pesquisador adotar qualquer valor acima deste, por exemplo, 10 explantes que correspondem à média dos tamanhos de parcela obtida pelo método de regressão quadrático.

\section{CONCLUSÃO}

Os tamanhos de parcelas variaram de acordo com o método de estimação utilizado. Foram encontrados valores para o tamanhoótimo de parcela de seis explantes pelo método de regressão linear e de dez explantes pelo modelo de regressão quadrático com platô.

Sugere-se utilizar parcelas formadas por 10 unidades básicas em experimentos com conservação in vitro da espécie Passiflora giberti N. E. Brown, pois foi o número de unidades que satisfez todos os tratamentos testados.

\section{AGRADECIMENTOS}

Os autores expressam seus agradecimentos ao Conselho Nacional de desenvolvimento Científico e Tecnológico (CNPq) e Fundação de Amparo à Pesquisa do Estado de Minas Gerais (FAPEMIG), pela bolsa e apoio financeiro concedidos.

\section{REFERÊNCIAS}

AIRES, P.S.R. et al. Efeito da concentração de vitaminas e das fontes de carbono no superbrotamento da mamona utilizado o genótipo BRS Nordestina. Revista de Biologia e Ciências da Terra, v.7, n.2, p.1-5, 2007.

ANDERSON, R.L.; NELSON, L.A. A family of models involving intersecting straight lines and concomitant experimental designs useful in evaluating response to fertilizer nutrients. Biometrics, v.31, n.2, p.303-318, 1975. Disponível em: <http://www.jstor.org/stable/2529422>. Acesso em: 15 nov. 2009. ISSN: 0006341X E-ISSN: 15410420.

COSTA, C.M., AYUB, R.A. Fluxo radicente na organogênese do maracujazeiro amarelo. Scientia Agricola, v.3, n.1-2, p.103-106, 2002.

DONATO, S.L.R. et al. Estimativas de tamanho de parcelas para avaliação de descritores fenotípicos em bananeira. Pesquisa Agropecuária Brasileira, v.43, n.8, p.957969, 2008. Disponível em: <http://www.scielo.br/ scielo.php? script=sci_arttext\&pid=S0100204X2008000800 $003 \& \operatorname{lng}=\mathrm{pt} \& \mathrm{nrm}=\mathrm{iso}>$. Acesso em:10 nov.09. doi:10.1590/S0100204X200800080000 3.

FARIA, G.A. et al. Meio de cultura e tipo de explante no estabelecimento in vitro de espécies de maracujazeiro. Bragantia, v.66, n.4, p.535-543, 2007. Disponível em: <http://www.scielo.br/ scielo.php? script $=$ sci_art text \& pid = S 0006 87052007000400002>. Acesso em: 17 jan. 2008. doi: 10.1590/ S0006-87052007000400002.

LE CLERG, E.L. Significance of experimental design in plant breeding. In: FREY, K.J. Plant breeding symposium. Ames: Iowa State University, 1967. p.243-313.

LESSMAN, K.J.; ATKINS, R.E. Optimum plot size and relative efficiency of lattice designs for grain sorghum yield test. Crop Science, v.3, n.6, p.477-481, 1963.

LIMA, E.C. et al. Callus induction in segments of Croton urucurana Baill. Ciência e Agrotecnologia, v.32, n.1, p.1722, 2008. Disponível em: <http://www.scielo.br/ scielo.php?script=sci_arttext $\&$ pid $=$ S141370542008000100002 $\& \operatorname{lng}=$ enenDirectory $\& n r m=i s o \&$ tlng=enenDirectory $>$. Acesso em: 20 out. 2009. doi: 10.1590/S1413-70542008000100002.

MARTINEZ, C.O. et al. Glifosate e glufosinato como agentes seletivos para transformação genética de maracujá amarelo (Passiflora edulis f. flavicarpa Deg.). Revista Brasileira de Herbicidas, v.3, p.18-34, 2005. Disponível em: <http:// www.rbherbicidas.com.br/index.php/rbh/article/view/34/27>. Acesso em: 19 out. 2009. ISSN (Online) 2236-1065.

MEIER, V.D.; LESSMAN, K.J. Estimation of optimum Field plot shape and size for testing yield in Crambe abyssinica Hochst. Crop Science, v.11, p.648-650, 1971. Disponível em: <http:// w w w. s c i e 1 o.b r / s c i e 1 o 0 r g / p h p / reflinks.php?refpid $=$ S14137054200700050002100006\&pid $=$ S141370542007000500021\&lng=en>. Acesso em: 26 out. 2009. IDS Number: K6734 ISSN: 0011-183X.

PARANAÍBA, P.F. et al. Tamanho ótimo de parcelas experimentais: proposição de métodos de estimação. Revista Brasileira de Biometria, v.27, n.2, p.255-268, 2009a.

PARANAÍBA, P.F. et al. Tamanho ótimo de parcelas experimentais: comparação de métodos em experimentos de trigo e mandioca. Revista Brasileira de Biometria, v.27, n. 1, p.81-90, 2009b.

PASSOS, I.R.S. et al. Utilização do acido giberélico para quebra de dormência de sementes de Passiflora nítida Kunth germinadas in vitro. Revista Brasileira de Fruticultura, v.26, n.2, p.380-381, 2004. Disponível em: <http://www.scielo.br/ scielo.php?pid=S010029452004000200051\&script=sci_abstra ct\&tlng=pt>. Acesso em: 02 maio, 2009. doi: 10.1590/S010029452004000200051.

R DEVELOPMENT CORE TEAM. R: a language and environment for statistical computing. Viena: $R$ Foundation for Statistical Computing. 2010. Disponível em: www.R-project.org. Acesso em: 15 nov. 2010.

RIBAS, A.F. et al. Misturas vitamínicas na regeneração do maracujazeiro amarelo (Passiflora edulis f. Flavicarpa Deg). Ciência Rural, v.32, n.2, p.237-241, 2002. Disponível em: <http://www.scielo.br/scielo.php? pid=S0103$84782002000200009 \&$ script $=$ sci_arttext $>$. Acesso em: 25 nov. 2009. doi: 10.1590/S0103-84782002000200009.

RIBEIRO, L.M. et al. Organagênese in vivo em acessos de maracujazeiro amarelo infectados pelo vírus CABMV. 
Unimontes Científica, v.8, n.1, p.87-98, 2006. Disponível em: <http://www.unimontes.br/unimontescientifica/revistas/ Revista\%20V8_N1/ARTIGOS/Organogenese_in_Vitro/ Organogenese_in_vitro\%20v8n1.pdf>. Acesso em: 26 out. 2009. ISSN $1519-2571$.

SCHABENBERGER, O.; PIERCE, F.J. Contemporary statistical models for the plant and soil sciences. 2.ed. Boca Raton: CRC, 2002. 738p.

SMITH, H.F. An empirical law describing heterogeneity in the yields of agricultural crops. Journal of Agricultural Science, Cambridge, v.28, n.1, p.1-23, 1938.

STORCK, L. et al. Comprimento e largura do tamanho ótimo da parcela experimental em batata. Ciência Rural, v.35, n.5, p.1043-1048, 2005. Disponível em: <http://www.scielo.br/ scielo.php?script $=\mathrm{sci}_{-}$art text\&pid=S $0103-$ $84782005000500009>$. Acesso em: 26 out. 2009. doi: 10.1590/S0103-84782005000500009.

TREVISAN, F.; MENDES, B.M.J. Optimization of in vitro organogenesis in passion fruit (Passiflora edulis f. Flavicarpa). Sciencia Agricola, v.62, n.4, p.346-350, 2005. Disponível em: $<$ ht t p ://www.scielo.br/scielo.php?pid=S $0103-$ 90162005000400007\&script=sci_arttext $>$. Acesso em: 24 nov 2009. doi: 10.1590/S0103-90162005000400007.

VILLA, F. et al. Cloreto de potássio e fosfato de sódio na multiplicação in vitro de amoreira preta cv Tupi. Ciência e Agrotecnologia, v.32, n.1, p.37-41, 2008. Disponível em: <http://www.scielo.br/scielo.php?pid=S1413$70542008000100005 \&$ script $=$ sci_arttext $>$. Acesso em: 20 mar. 2010. doi: 10.1590/S1413-70542008000100005. 